\title{
Análise da Produção Científica Sobre Envelhecimento e Espiritualidade
}

\author{
Chaves, Lindanor Jacó; Buriti, Marcelo de Almeida; Gil, Claudia Aranha; Rodrigues, \\ Graciele Massoli \\ Universidade São Judas Tadeu — lindajchaves@gmail.com
}

O envelhecimento populacional é um grande desafio para o Brasil e o mundo, e tem estimulado estudos e investigações em diversas áreas do conhecimento. a espiritualidade tem sido considerada ao longo dos anos como fator de satisfação e até mesmo de consolo para diferentes momentos da vida. Assim, o objetivo desta pesquisa foi identificar e analisar artigos sobre Envelhecimento e Espiritualidade publicados na SCIELO no período de 2000 a 2012. o conjunto de estudos analisados foi identificado na base de dados SCIELO e a localização dos artigos foi realizada nos meses de agosto a outubro de 2012 no período de tempo pesquisado foram encontradas 11 publicações referentes ao tema em questão. Os resultados demonstram que mais de $80 \%$ das pesquisas são descritivas, entre os estudos analisados a temática mais abordada foi Avaliação da Qualidade de vida e Saúde encontrada em mais de $45 \%$ dos trabalhos. Verificou-se ainda que a maior parte dos estudos são qualitativos (45,45\%) e que todos os artigos analisados são de delineamento de levantamento. nas pesquisas de campo, os instrumentos mais utilizados foram os questionários; quanto aos objetivos mais de $54 \%$ das pesquisas atendem aos objetivos propostos inicialmente pelos pesquisadores; entretanto, entre os estudos analisados, apenas três apresentam o conceito de espiritualidade. o reduzido número de publicações nessa temática com foco em idosos demonstra a necessidade de pesquisas mais direcionadas a esse grupo e suas especificidades, bem como a elaboração de instrumentos adequados de avaliação, uma vez que a maioria dos estudos utiliza-se de instrumentos genéricos na mensuração do impacto dessa espiritualidade na vida dos idosos. Assim, concluiu-se que a produção científica sobre espiritualidade e sua relação com o envelhecimento, e a população idosa de forma geral, é um campo de investigação em expansão, que vem sendo estudada a partir da avaliação de saúde e qualidade de vida dos idosos, e que o maior número de pesquisas vem sendo realizada por pesquisadores do gênero feminino. Nesse contexto, a interdisciplinaridade nos estudos com essa temática é de fundamental importância, por possibilitar a inter-relação entre as ciências, permitindo, que o conhecimento produzido possa ser utilizado em diferentes áreas do conhecimento. o maior número de pesquisas qualitativas de delineamento descritivo demonstra o interesse pela subjetividade do idoso. As temáticas abordadas nos estudos e os objetivos propostos em sua grande maioria não visam uma abordagem que estude especificamente a relação entre os aspectos da espiritualidade e o processo de envelhecimento. Há uma carência também na conceituação de espiritualidade nos artigos, e essa ausência prejudica a compreensão do papel da espiritualidade na saúde e na qualidade de vida do idoso.

Palavras-chave: Idosos, saúde, espiritualidade

Chaves, Lindanor Jacó; Buriti, Marcelo de Almeida; Gil, Claudia Aranha; Rodrigues, Graciele Massoli. Análise da Produção Científica Sobre Envelhecimento e Espiritualidade.. In: Anais do Congresso Internacional de Humanidades \& Humanização em Saúde [= Blucher Medical Proceedings, num.2, vol.1]. São Paulo: Editora Blucher, 2014.

ISSN 2357-7282

DOI 10.5151/medpro-cihhs-10280 